\title{
MENGENAL SISTEM KOMPUTER
}

\author{
ANTONIO ALFAREZ HIDAYAT \\ 195120004 \\ FAKULTAS KOMPUTER \\ antonio.student@umitra.ac.id
}

\section{RESUME}

Sistem komputer adalah suatu jaringan elektronik yang terdiri dari perangkat lunak dan perangkat keras yang melakukan tugas tertentu seperti menerima input, memproses input, menyimpan perintah-perintah, dan menyediakan output dalam bentuk informasi.

Selain itu dapat pula diartikan sebagai elemen-elemen yang terkait untuk menjalankan suatu aktivitas dengan menggunakan komputer. Komputer dapat membantu manusia dalam pekerjaan sehari-harinya, pekerjaan itu seperti: pengolahan kata, pengolahan angka, dan pengolahan gambar.

\section{- Komponen dari Sistem Komputer}

Elemen atau komponen dari sistem komputer terdiri dari manusia (brainware), perangkat lunak (software), set instruksi (instruction set), dan perangkat keras (hardware). Dengan demikian komponen tersebut merupakan elemen yang terlibat dalam suatu sistem komputer. 


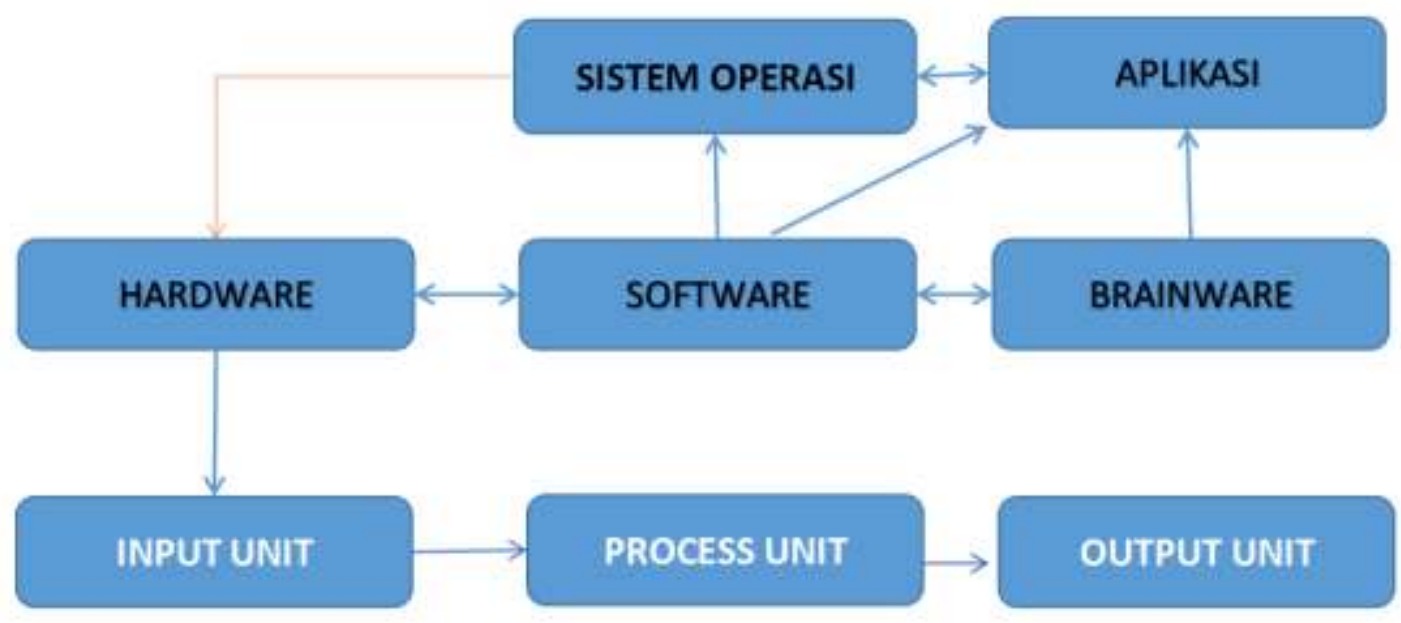

\section{A. HARDWARE}

adalah Hardware perangkat keras komputer yang terdiri dari 3 unit utama yaitu Input Unit, Processing Unit dan Output Unit.

1. Input Unit

Input Unit merupakan bagian dari perangkat keras yang berfungsi sebagai alat untuk memasukan data dan lain sebagainya ke dalam komputer. Perangkat yang termasuk ke dalam input unit diantaranya adalah sebagai berikut.

- Keyboard

- Mouse

- Camera digital

- Scanner

- Web Camera

- Joystik

- Microphone

- dll 


\section{Processing Unit}

Processing unit biasa juga di sebut CPU (Central Processing Unit) yang merupakan jantung dari komputer. Bagian ini melakukan pekerjaan utama seperti proses, perhitungan, logika, kontrol,pengaturan hubungan kinerja natar komponen serta mengalokasikan tempat sementara maupun permanen.

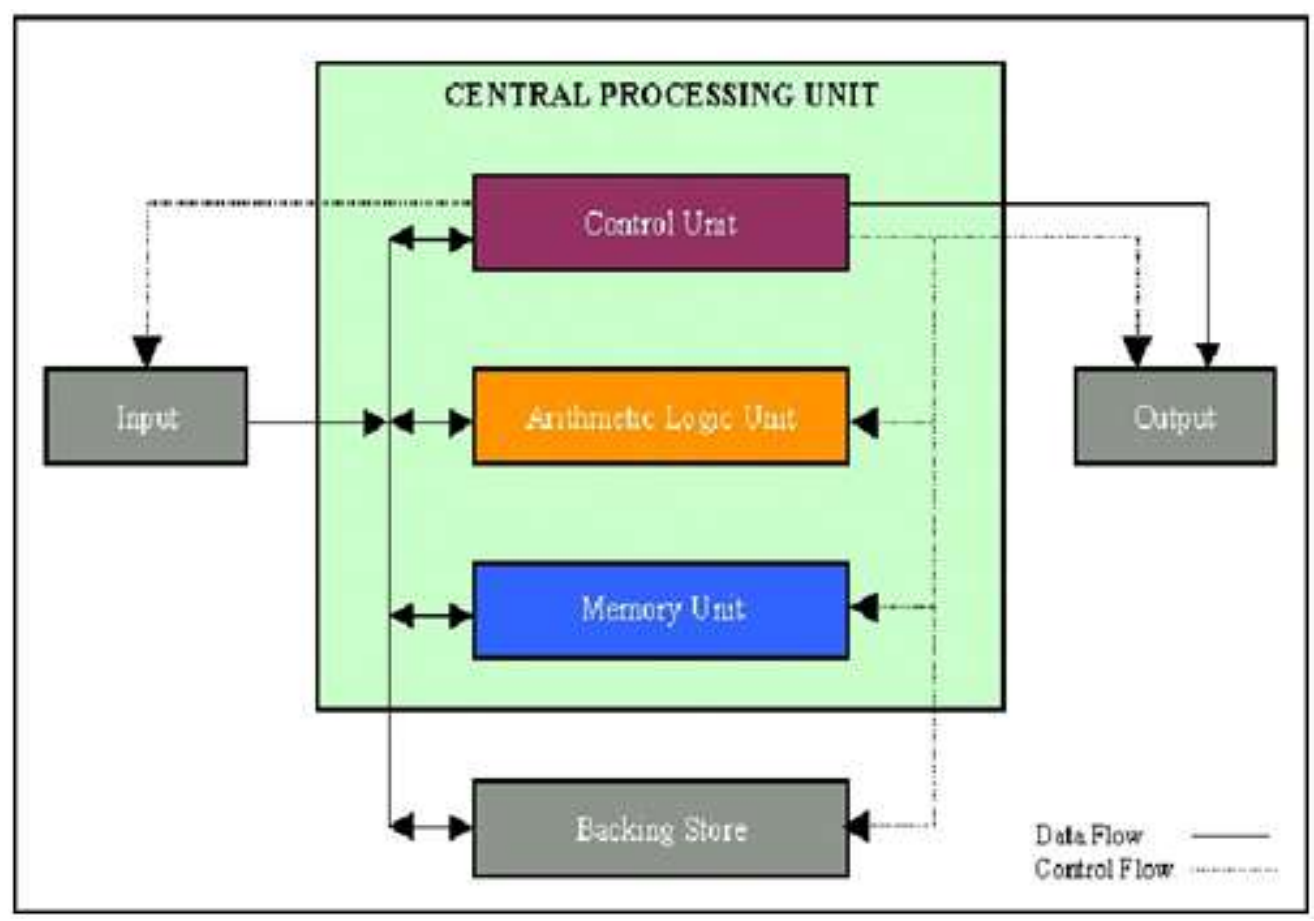

Secara umum CPU mempuyai 3 komponen utama yaitu:

- Aritmetic dan logical Unit (ALU)

Tugasnya adalah melakukan perhitungan yang bersifat aritmatik serta melakukan keputusan dari operasi logika dan manipulasi bit sesuai dengan instruksi program. 


\section{Resume Upload OSF}

- Control Unit

Tugasnya mengatur dan mengendalikan semua peralatan yang ada pada sistem komputer serta mengatur kapan alat input menerima dan kapan alat output menampilkannya di monitor (Intruction Cycle)

- Main memory (main storage)

merupakan tempat atau media yang digunakan untuk menyimpan data yang akan atau sedang diolah sistem komputer. Main Memory terbagi menjadi 2 bagian yaitu:

1.ROM (Read only Memory), ROM merupakan memori permanen yang terdapat pada sistem komputer yang sudah disusun dan dibuat oleh pabrik, biasanya tidak bisa diubah oleh user komputer. Rom terdiri dari program pokok untuk konfigurasi sistem komputer sepeti BIOS, BASIC dan BootSrap Loader. Sekarang ini ROM yang dipakai untuk bios menggunakan teknologi CMOS (Complementary Metal Oxide Semiconductor), yang dapat mengubah konfigurasi BIOS bila perlu sehingga pemakai komputer dapat mengubah sistem BIOS. ROM tetap berada di dalam komputer pada saat apapun. Sinyal di dalam ROM ini yang mengatur segala tugas CPU saat komputer mulai diaktifkan.

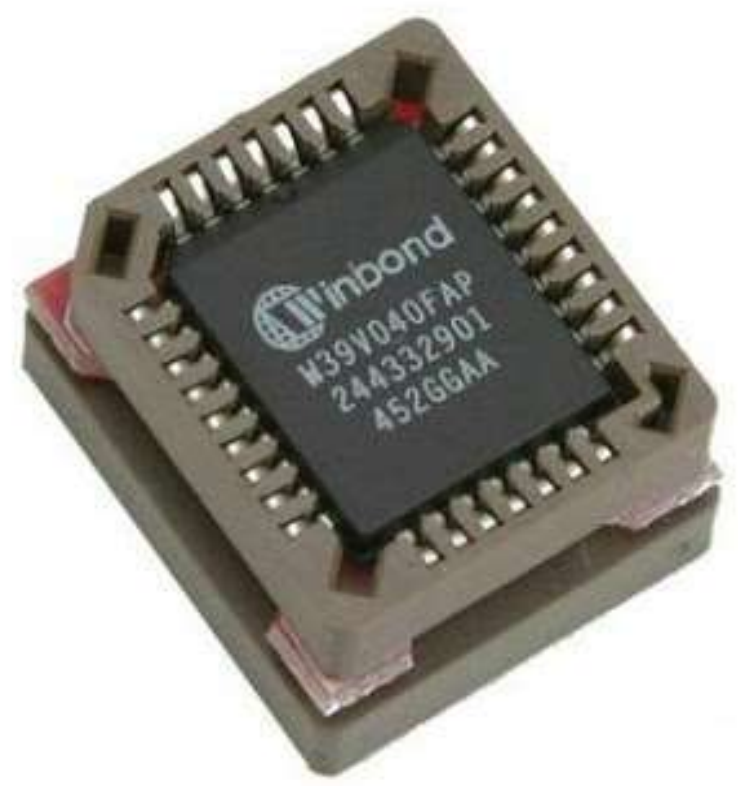


2.RAM (Random Access Memory), Semua data yang dimasukan melalu alat input pada setiap aplikasi akan dimasukan terlebih dahulu ke dalam main memory ini. Data-data yang terdapat dalam ram ini hanya bersipat sementara. apabila komputer dimatikan, maka data tersebut akan hilang.

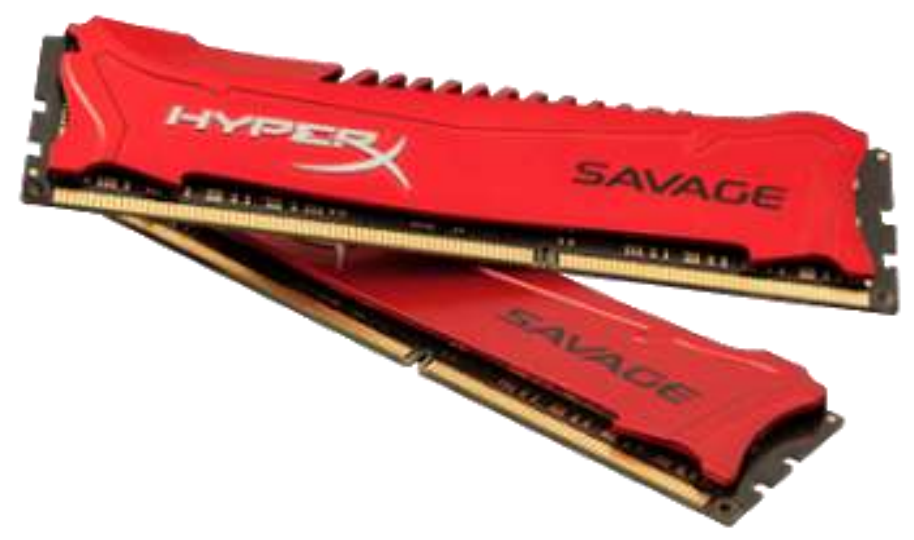

\section{Output Unit}

Output unit merupakan perangkat keras yang berfungsi untuk menyajikan output dari proses yang sedang bekerja pada komputer. device yang termasuk ke dalam output unit ini adalah diantaranya adalah sebagai berikut.

- Monitor

- Printer

- Projector

- speaker

- dll

\section{B. SOFTWARE}

Software atau perangkat lunak berfungsi sebagai pengatur kerja komponen dan semua instruksi yang mengarah pada sistem komputer. Perangkat lunak menjembatani interaksi user dengan komputer yang hanya memahami bahasa mesin. Secara Umum perangkat lunak dibagi menjadi menjadi 2 yaitu: 
1. Operating System

2. Application System

Sistem Operasi ( Operating System )

Operating System merupakan perangkat lunak yang berfungsi untuk mengkonfigurasi komputer agar dapat menerima perintah dasar yang diberikan sebagai masukan atau input. yang termasuk kedalam operating system diantaranya adalah MS-DOS, LINUX, UNIX, FREE BSD, OS/2, SUN (java), Windows, Macintosh, Novell, dan untuk sekarang ini ditambah lagi OS Android, Blackberry, windows mobile yang digunakan pada perangkat mobile.


1.Sistem Operasi Windows Windows adalah sebuah Sistem Operasi yang dikembangkan oleh Microsoft Corporation yang menggunakan antar muka dengan berbasikan GUI (GraphicalUser Interface) misalnya Ms-Dos, windows 98, windows $\mathrm{xp}$, windows 7 , windows 8 , dan windows 10 
2.Sistem Operasi Linux Linux merupakan kloningan dari MINIX (turunan dari UNIX). Sistem operasi ini juga terkenal dan banyak orang yang menggunakannya. Linux disusun berdasarkan standar Sistem Operasi POSIX yang diturunkan dari UNIX itu sendiri. Ada beberapa macam Distro Linux, seperti : Debian, Lycoris, Xandros, Lindows, Linare, Linux-Mandrake, RedHat Linux, Slackware, Knoppix, Fedora, Suse, Ubuntu.

3.Sistem Operasi MACINTOSH (mac OS), Mac OS diciptakan oleh perusahaan Apple Inc. dengan desain yang elegan tapi mudah digunakan oleh pengguna. Mac OS merupakan sistem operasi pertama yang menggunakan GUI (Graphical User Interface). Kata Macintosh diambil dari nama apel kesukaan Jef raskin, McIntosh. Diperkenalkan pada tahun 1984, dan menjadi salah satu raksasa penguasa Operating System sekarang. Sejak tahun 2006, MAC OS telah memiliki kompatibilitas dengan arsitektur Power PC maupun x86.

4.Sistem Operasi Symbian Symbian adalah sistem operasi tak bebas yang dikembangkan oleh Symbian Ltd. yang dirancang untuk digunakan pada peralatan bergerak atau ponsel. Jenis Os ini mudah kita temui di ponsel-ponsel produk nokia dan beberapa produk Sony. Akan tetapi sekarang Pamor dari OS ini sedikit bergeser karena kalah popular dengan beberapa os baru seperti android.

5.Sistem Operasi Android, Android adalah Os linux yang dikembangkan dan di buat untuk aplikasi Mobile atau ponsel. Android menyediakan platform terbuka bagi para pengembang untuk menciptakan aplikasi mereka sendiri untuk digunakan oleh bermacam peranti bergerak. Android sendiri sudah mengalami banyak perubahan.

6.System operasi Palm Palm adalah Os untuk mobile yang dikembangkan oleh Palm, Inc. Yaitu sebuah perusahaan multinasional yang bermarkas di Sunnyvale, California, Amerika Serikat. Contoh produk yang menanamkan sistem operasi Palm adalah Palm Treo 680 Smartphone ini menggunakan system operasi Palm, yaitu Palm OS 5.4.9 dengan prosesor Intel PXA270, 312MHz. Beberapa fitur yang ditawarkan adalah 
Pocket Express, Microsoft Media Player, Palm files, PDF viewer, Adobe Acrobat reader, eReader, Pocket Tunes, dan Document To Go.

7. System Windows Mobile Windows Mobile adalah Sistem Operasi yang dibuat oleh Microsoft untuk peralatan bergerak (mobile). Pertama kali Windows Mobile muncul sebagai sistem operasi Pocket PC 2000, sebagian besar perangkat yang menggunakan Windows Mobile memiliki stylus pen yang digunakan sebagai alat untuk memberi perintah dengan menyentuhkannya pada layar

8.Sistem Operasi BlackBerry BlackBerry OS adalah sebuah Sistem Operasi Mobile yang dikembangkan oleh Research In Motion untuk perusahaan BlackBerry garis smartphone untuk perangkat genggam. Sistem operasi ini menyediakan multitasking dan mendukung perangkat input khusus yang telah diadopsi oleh RIM untuk digunakan dalam handheld, khususnya trackwheel, trackball, dan yang paling baru, yang trackpad dan touchscreen.

\section{A. ID SECURITY}

QWTD44112377-ASP-524414475

\section{B. REFERENCE}

[1] O. M. Febriani and A. S. Putra, "Sistem Informasi Monitoring Inventori Barang Pada Balai Riset Standardisasi Industri Bandar Lampung," J. Inform., vol. 13, no. 1, pp. 90-98, 2014.

[2] A. S. Putra, "Paperplain: Execution Fundamental Create Application With Borland Delphi 7.0 University Of Mitra Indonesia," 2018.

[3] A. S. Putra, "2018 Artikel Struktur Data, Audit Dan Jaringan Komputer," 2018.

[4] A. S. Putra, "ALIAS MANAGER USED IN DATABASE DESKTOP STUDI CASE DB DEMOS."

[5] A. S. Putra, "COMPREHENSIVE SET OF PROFESSIONAL FOR DISTRIBUTE COMPUTING."

[6] A. S. Putra, "DATA ORIENTED RECOGNITION IN BORLAND DELPHI 7.0."

[7] A. S. Putra, "EMBARCADERO DELPHI XE 2 IN GPU-POWERED FIREMONKEY APPLICATION." 
[8] A. S. Putra, "HAK ATAS KEKAYAAN INTELEKTUAL DALAM DUNIA TEKNOLOGY BERBASIS REVOLUSI INDUSTRI 4.0."

[9] A. S. Putra, "IMPLEMENTASI PERATURAN PERUNDANGAN UU. NO 31 TAHUN 2000 TENTANG DESAIN INDUSTRI BERBASIS INFORMATION TECHNOLOGY."

[10] A. S. Putra, "IMPLEMENTATION OF PARADOX DBASE."

[11] A. S. Putra, "IMPLEMENTATION OF TRADE SECRET CASE STUDY SAMSUNG MOBILE PHONE."

[12] A. S. Putra, "IMPLEMENTATION PATENT FOR APPLICATION WEB BASED CASE STUDI WWW. PUBLIKLAMPUNG. COM."

[13] A. S. Putra, "IMPLEMENTATION SYSTEM FIRST TO INVENT IN DIGITALLY INDUSTRY."

[14] A. S. Putra, "MANUAL REPORT \& INTEGRATED DEVELOPMENT ENVIRONMENT BORLAND DELPHI 7.0."

[15] A. S. Putra, "PATENT AS RELEVAN SUPPORT RESEARCH."

[16] A. S. Putra, "PATENT FOR RESEARCH STUDY CASE OF APPLE. Inc."

[17] A. S. Putra, "PATENT PROTECTION FOR APPLICATION INVENT."

[18] A. S. Putra, "QUICK REPORT IN PROPERTY PROGRAMMING."

[19] A. S. Putra, "REVIEW CIRCUIT LAYOUT COMPONENT REQUIREMENT ON ASUS NOTEBOOK."

[20] A. S. Putra, "REVIEW TRADEMARK PATENT FOR INDUSTRIAL TECHNOLOGY BASED 4.0."

[21] A. S. Putra, "TOOLBAR COMPONENT PALLETTE IN OBJECT ORIENTED PROGRAMMING."

[22] A. S. Putra, "WORKING DIRECTORY SET FOR PARADOX 7."

[23] A. S. Putra, "ZQUERY CONNECTION IMPLEMENTED PROGRAMMING STUDI CASE PT. BANK BCA Tbk."

[24] A. S. Putra, D. R. Aryanti, and I. Hartati, "Metode SAW (Simple Additive Weighting) sebagai Sistem Pendukung Keputusan Guru Berprestasi (Studi Kasus: SMK Global Surya)," in Prosiding Seminar Nasional Darmajaya, 2018, vol. 1, no. 1, pp. 85-97.

[25] A. S. Putra and O. M. Febriani, "Knowledge Management Online Application in PDAM Lampung Province," in Prosiding International conference on Information Technology and Business (ICITB), 2018, pp. 181-187.

[26] A. S. Putra, O. M. Febriani, and B. Bachry, "Implementasi Genetic Fuzzy System Untuk Mengidentifikasi Hasil Curian Kendaraan Bermotor Di Polda Lampung," SIMADA (Jurnal Sist. Inf. dan Manaj. Basis Data), vol. 1, no. 1, pp. 21-30, 2018.

[27] A. S. Putra, H. Sukri, and K. Zuhri, "Sistem Monitoring Realtime Jaringan Irigasi Desa (JIDES) Dengan Konsep Jaringan Sensor Nirkabel," IJEIS (Indonesian J. Electron. Instrum. Syst., vol. 8, no. 2, pp. 221-232.

[28] D. P. Sari, O. M. Febriani, and A. S. Putra, "Perancangan Sistem Informasi SDM Berprestasi pada SD Global Surya," in Prosiding Seminar Nasional Darmajaya, 2018, vol. 1, no. 1, pp. 289-294. 


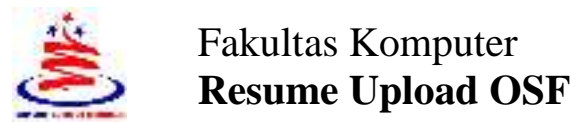

ANTONIO ALFAREZ HIDAYAT 